\title{
Editorial
}

\section{The Making of MOBILLE a Year Later}

\author{
Sonia Rocca \\ World Languages Department, Lycée Français de New York, New York, NY 10021, USA; srocca@lfny.org
}

Received: 20 April 2020; Accepted: 23 April 2020; Published: 27 April 2020

Over a year has passed since the 2019 MOBILLE International Conference took place at the Lycée Français de New York. During the February recess, this iconic institution of the Upper East Side hosted a novel conference whose primary goal was to bring together researchers and practitioners from all over the world in an academic forum to discuss the impact of technological advancements on the learning and teaching of languages. With around one hundred participants attending thirty-nine sessions in two days, MOBILLE was indeed mobile, going by so fast in a swirl of synergies that channeled the conference motto: "CONNECT-INTERACT-LEARN".

The purpose of this editorial is to introduce the conference proceedings featured in this special issue. But the first and foremost goal is to revivify MOBILLE, highlighting the contributions that embodied its spirit. Starting from the keynote address that opened the conference and set its overall tone, Ortega (2019) focused her presentation on the benefits of mobile language learning experiences. She spotlighted areas where practitioners and researchers have been working together, citing current research on various types of digital language learning - naturalistic vs. instructed, incidental vs. intentional, in-class vs. out-of-class. She insisted on the importance of out-of-class digital lives, e.g., gaming, social media, fandom and communities of interest. She emphasized the classroom integration of such rich digital lives, surmising a two-way flow, where, on the one hand, digital wilds are connected to in-class practices, and, on the other hand, digital literacies acquired in the class are transferred to life outside the class. As technological advancements create new needs and transform old ones, she encouraged practitioners and researchers to continue working together on a task-based approach that promotes authenticity in the learning as well as in the teaching.

In her keynote address, Ortega drove home MOBILLE's raison d'être as the communing of mobile language learning experiences by practitioners and researchers working together. The eight publications of this special issue show how multifaceted these experiences were-in fact, as multifaceted as the conference that hosted them. Since MOBILLE was founded in a bilingual French-English school, and in keeping with the bilingual ethos of the school, sessions could be either in French or in English. An assortment of languages was featured, either as source or target languages. Most of the presentations dealt with the learning of English, but Spanish, Catalan, French, Italian, Chinese, Japanese, Finnish, Dutch, Turkish and Coptic were also represented. MOBILLE was a truly international endeavor, with participants affiliated with institutions in North America (US, Canada, Mexico), South America (Argentina, Peru, Brazil), Europe (UK, Spain, France, Germany, Belgium, Finland, Greece) and East Asia (China, Japan, The Philippines).

The session types matched the various needs and preferences of the presenters and participants alike. The presentations could either be research-oriented, practice-oriented or discussion-oriented. As a special feature, those who were unable to present in person could do so virtually either by video-conference with a co-presenter on site, or by uploading pre-recorded videos on the MOBILLE Lycée Français de New York YouTube Channel. There were also workshops for a longer, more interactive hands-on experience. All the session types are represented in this special issue: workshops (Dershowitz 2019), research-oriented presentations (Ho 2019; Eisenstein Ebsworth et al. 2019), practice-oriented presentations (Lehtonen 2019), discussion-oriented presentations (Karttunen and Juusola 2019) and virtual presentations 
(Benabdelkader 2019; Nobrega and Rozenfeld 2019). All these papers underwent two rounds of peer review before getting accepted for publication.

Regardless of the format, the MOBILLE sessions sparked engagement and interaction, so much so that time allocated never seemed enough and the exchanges kept burgeoning before and after sessions among participants from all sorts of professional backgrounds: students, teachers, lecturers, researchers, professors, administrators, counsellors, engineers, technicians and technology officers. MOBILLE gave voice to those who were keen on sharing their work whatever stage of development it was at. It is hard to find a common denominator among such a constellation of geographical, cultural and professional backgrounds. What seemed to be recurring was a shared interest in technological innovation and the learning opportunities it promotes, an interest that is also shared by the eight papers below.

I would like to start with a paper on how social media can contribute to the revitalization of an endangered language. To that end, Deschene (2019) created digital resources for Coptic language learning and posted them on Facebook, Instagram and Twitter. Social media is increasingly being utilized as a pedagogical tool. Rosell-Aguilar (2019) reports on the benefits of Twitter for language learning in a study with 370 participants. Llopis-Garcia (2019) argues for the use of Twitter to foster student analyses of the Spanish linguistic landscapes in New York City. Li (2019) illustrates a multimedia project to promote the development of Chinese-English bi-cultural awareness via WeChat. Whatsapp was utilized for an English summer course in Spain (Andria 2019), for teacher education in Brazil (Braga 2019) and for out-of-class communication among beginner students of Spanish (González-Gómez and Asención-Delaney 2019).

Online courses are growing increasingly popular. The most popular of them are convenient, flexible and interactive. Eisenstein Ebsworth et al. (2019) review an online course about the United Nations for English language learners in a US high school. Karttunen and Juusola (2019) discuss how to maintain quality in higher education online language courses for immigrants in Finland. Hobgood and Lindsey (2019) offer a range of strategies to build stronger teacher-student connections in online language learning environments.

YouTube's audiovisual capabilities open multimodal pathways to language learning. Ho (2019) suggests that YouTube videos teaching interview job skills create a comprehensive learning experience that goes beyond the learning of English to embrace semiotics. Audiovisuals have always been an asset in the language classroom and current technological sophistication has increased their potential. Maroto (2019) presents digital oral video material to improve engineering undergraduates' oral skills in Spain. Daccord (2019) leads a workshop on students' video reflections submitted through Flipgrid and Recap. Fajardo (2019) leads a workshop on how to use video-recorded natural conversations to teach oral interaction. Benabdelkader (2019, below) examines the Skype video conversations of three pairs of interlocutors where English and French alternate as first and second/foreign languages. Skype also proves invaluable in the teaching of English to the visually impaired in Brazil (Retorta 2019).

Audio and video are essential components of virtual reality. Toyoda (2019) argues for the use of virtual reality mobile apps to teach non-verbal communication skills to Japanese learners of English. Hoy (2019) overviews low-cost mobile virtual reality technologies and shows how they can be integrated into a communicative language classroom. Berti (2019) investigates the virtual reality experiences of Italian sites by undergraduates in the US who utilized Google Cardboard and dedicated smartphone applications. Mills et al. (2019) report on students of French immersed in the virtual reality narratives of four Parisians who documented their lives with a virtual reality camera. Aguirre and Amano (2019) showcase virtual reality games for disadvantaged learners of English in a Mexican college. Nobrega and Rozenfeld (2019) present an ongoing project in the teaching of French through virtual reality in a Brazilian public secondary school.

The language classroom tends to favor communicative activities that encourage students to speak. Most of the MOBILLE sessions focused on the development of oral skills, but a couple of presentations dealt with the development of writing. Technological advancements add a multimedia dimension to language tasks, whether oral or written. Lehtonen (2019) illustrates a compare/contrast writing 
assignment about campus spaces that he designed for his ESL composition courses at a US university. Hadingham and Rappeneker (2019) show how Web 2.0 software like Adobe Spark Page and Microsoft Sway can be utilized to spur English learners' creativity and critical thinking in e-journal writing.

This overview culminates with a paper on the importance of an ethics-based computer science, an issue that arose in several places in the conference. In a world where technology is ubiquitous and pervasive, Dershowitz (2019) calls for an ethical focus in teaching children how to use technology and underscores the challenges and opportunities of such teaching in bilingual multicultural schools. She also strongly advocates for more student voice in technology education.

In this overview, I have tried to weave a conceptual thread among a conference that was a maze of topics and themes. Besides the already stated shared interest in technological innovation and the learning opportunities it promotes, what these contributions seem to have in common is a redefinition of what language learning is about, a perennial issue that is as old as ancient times. As technological progress reshapes the what, how, when, where and why, all these papers, in one way or another, are concerned with how teaching and learning get enhanced while teachers and learners get empowered. As mobile technology goes from anytime-anywhere to everytime-everywhere, mobility becomes a here and now experience that never stops getting better. At the heart of MOBILLE lies mobility, which can be defined by constantly evolving learning experiences that cutting-edge technology optimizes.

Funding: MOBILLE International Conference was funded by the Lycée Français de New York.

Conflicts of Interest: The author declares no conflict of interest.

\section{References}

Aguirre, Brisia, and Michiko Amano. 2019. Game It ‘Till You Make It: VR Games for Disadvantaged ESL Low Achievers. Paper presented at MOBILLE International Conference, New York, NY, USA, February 21-22; Available online: https://youtu.be/b17iXhpOys0 (accessed on 7 April 2020).

Andria, Maria. 2019. Mobile Language Learning: The Use of 'WhatsApp' Application in an EFL Classroom. Paper presented at MOBILLE International Conference, New York, NY, USA, February 21-22.

Benabdelkader, Amira. 2019. Expert-Novice Negotiation within Learning Opportunities in Online Intercultural Interactions. Languages 4: 14. [CrossRef]

Berti, Margherita. 2019. Cultural Awareness in the Language Classroom: A Virtual and Immersive Approach. Paper presented at MOBILLE International Conference, New York, NY, USA, February 21-22. Available online: https://youtu.be/Z-JG0wMlTqA (accessed on 7 April 2020).

Braga, Junia. 2019. Using WhatsApp in Teacher Education: A Study in the Perspective of Complexity. Paper presented at MOBILLE International Conference, New York, NY, USA, February 21-22.

Daccord, Tom. 2019. High Velocity Video Reflection in the Language Classroom. Paper presented at MOBILLE International Conference, New York, NY, USA, February 21-22.

Dershowitz, Adena. 2019. Ethics-Based Computer Science in Bilingual and Multicultural Schools. Languages 4: 87. [CrossRef]

Deschene, D. Nicole. 2019. Coptic Language Learning and Social Media. Languages 4: 73. [CrossRef]

Eisenstein Ebsworth, Miriam, Chencen Cai, and Lauren McCoy. 2019. Adolescent ELLs Improve Their Academic English while Learning about the UN Online. Languages 4: 9. [CrossRef]

Fajardo, Guadalupe Ruiz. 2019. Input for Interaction: The Columbia Corpus of Conversations in Spanish. Paper presented at MOBILLE International Conference, New York, NY, USA, February 21-22.

González-Gómez, Ana, and July Asención-Delaney. 2019. WhatsApp in Spanish Language Instruction-Fostering Interpersonal Communication in the L2. Paper presented at MOBILLE International Conference, New York, NY, USA, February 21-22. Available online: https://youtu.be/yGjshjENisY (accessed on 7 April 2020).

Hadingham, Oliver, and Joshua Rappeneker. 2019. How Web 2.0 Tools Can Rejuvenate Journal Writing. Paper presented at MOBILLE International Conference, New York, NY, USA, February 21-22.

Ho, Wing Yee Jenifer. 2019. Developing Professional Communication: The Construction of a Multimodal Understanding of Job Interviews. Languages 4: 5. [CrossRef] 
Hobgood, Bobby, and Barbara Lindsey. 2019. Building Stronger Connections with your Online or Hybrid Students. Paper presented at MOBILLE International Conference, New York, NY, USA, February 21-22. Available online: https://youtu.be/NOM4xySUA-I (accessed on 7 April 2020).

Hoy, Trent. 2019. Beyond Simulation: VR as a Creative and Communicative Medium for Language Learning. Paper presented at MOBILLE International Conference, New York, NY, USA, February 21-22.

Karttunen, Miia, and Sirpa Juusola. 2019. Maintaining Quality Online: Piloting an Online Language Course for Immigrants in Finland. Languages 4: 25. [CrossRef]

Lehtonen, Jonathan. 2019. Ecocomposition in the ESL Classroom: The Campus Space Compare and Contrast Assignment. Languages 4: 28. [CrossRef]

Li, Zhengjie. 2019. Developing Idiomatic Competence via Digital Affordances on WeChat: A Sociocultural Approach. Paper presented at MOBILLE International Conference, New York, NY, USA, February 21-22.

Llopis-Garcia, Reyes. 2019. Twitter and the City: The Linguistic Landscape of NYC through Social Media. Paper presented at MOBILLE International Conference, New York, NY, USA, February 21-22.

Maroto, Nava. 2019. Development of Educational Mini-Videos to Enhance Oral Communication Skills. Paper presented at MOBILLE International Conference, New York, NY, USA, February 21-22.

Mills, Nicole, Chris Dede, and Arnaud Dressen. 2019. Cultural Immersion in Virtual Reality Narratives. Paper presented at MOBILLE International Conference, New York, NY, USA, February 21-22.

Nobrega, Felipe Augusto, and Cibele Cecílio de Faria Rozenfeld. 2019. Virtual Reality in the Teaching of FLE in a Brazilian Public School. Languages 4: 36. [CrossRef]

Ortega, Lourdes. 2019. Harnessing the Power of Digital Technologies for Language Learning: Practitioners and Scholars Working Together. Paper presented at MOBILLE International Conference, New York, NY, USA, February 21-22. Available online: https://youtu.be/1QLfVZawYmk (accessed on 28 March 2020).

Retorta, Miriam Sester. 2019. The Use of Skype on Smartphones in the Teaching of English to the Visually-Impaired. Paper presented at MOBILLE International Conference, New York, NY, USA, February 21-22. Available online: https://youtu.be/sqYdqY5oPCA (accessed on 7 April 2020).

Rosell-Aguilar, F. 2019. Can You Learn Languages Using Twitter? Paper presented at MOBILLE International Conference, New York, NY, USA, February 21-22.

Toyoda, Noricco. 2019. Possibility of ESL/JSL Non-Verbal Communication Learning with VR. Paper presented at MOBILLE International Conference, New York, NY, USA, February 21-22.

(C) 2020 by the author. Licensee MDPI, Basel, Switzerland. This article is an open access article distributed under the terms and conditions of the Creative Commons Attribution (CC BY) license (http://creativecommons.org/licenses/by/4.0/). 